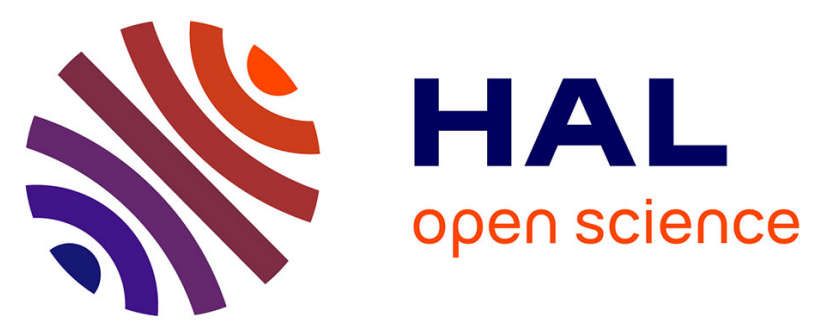

\title{
Subject-specific Center of Mass Estimation for In-home Rehabilitation - Kinect-Wii board vs. Vicon-Force plate
}

Alejandro González, Mitsuhiro Hayashibe, Philippe Fraisse

\section{To cite this version:}

Alejandro González, Mitsuhiro Hayashibe, Philippe Fraisse. Subject-specific Center of Mass Estimation for In-home Rehabilitation - Kinect-Wii board vs. Vicon-Force plate. Pons, José L. and Torricelli, Diego and Pajaro, Marta. Converging Clinical and Engineering Research on Neurorehabilitation, 2, Springer, pp.705-709, 2012, Biosystems \& Biorobotics (1), 978-9-642-34545-6. 10.1007/978-3-64234546-3_114. lirmm-00734972

\section{HAL Id: lirmm-00734972 \\ https://hal-lirmm.ccsd.cnrs.fr/lirmm-00734972}

Submitted on 5 Dec 2012

HAL is a multi-disciplinary open access archive for the deposit and dissemination of scientific research documents, whether they are published or not. The documents may come from teaching and research institutions in France or abroad, or from public or private research centers.
L'archive ouverte pluridisciplinaire $\mathbf{H A L}$, est destinée au dépôt et à la diffusion de documents scientifiques de niveau recherche, publiés ou non, émanant des établissements d'enseignement et de recherche français ou étrangers, des laboratoires publics ou privés. 


\title{
Subject-specific Center of Mass Estimation for In-home Rehabilitation - Kinect-Wii board vs. Vicon-Force plate
}

\author{
Alejandro González, Mitsuhiro Hayashibe, and Philippe Fraisse
}

\begin{abstract}
An increasingly aging society creates the need for a reliable evaluation of postural stability, specially for rehabilitation. Estimation of a subject's center of mass (CoM) is important for the assessment of unsupported, stable standing. A portable, in-home estimation of CoM can be used as a rehabilitation tool and could be achieved using a Microsoft's Kinect. To validate this approach we compare the performance of two statically equivalent serial chains. One of them was identified using a Kinect and a Wii board, while the other one was obtained from measurements performed with a motion capture system and a force plate. Their similar performance on a validation set indicates that it is feasible to perform subjectspecific center of mass estimation in the home environment.
\end{abstract}

\section{INTRODUCTION}

Our society is aging rapidly. Currently, a little under $8 \%$ of the world's population is 65 or older and this percentage is expected to reach $16 \%$ by 2050 [1]. The growth in the elderly population is more accentuated in developed countries where life expectancy continues to rise. As a result, the number of patients with motor function disorders can drastically increase while the ability to care for them will be limited by public expenditure and human resources. Thus, there is high demand for computer-aided tools which support inhome rehabilitation. Human static stability while standing is dependent on the relative position of the ground projection of the center of mass $(\mathrm{CoM})$ to the support polygon described by the subject's feet. The most common methods for CoM estimation require either knowledge of the subject's pose, or measurement of his center of pressure (CoP) [2], [3]. In both cases high-end equipment is required. Such equipment is often expensive and can be accesible only inside the laboratory. The equipment set up is also complicated. Those constraints make in-home use unlikely.

The statically equivalent serial chain (SESC) method simplifies calculation of the subject's CoM. The SESC's parameters can be identified from a set of known CoM ground projections, which are in turn estimated by CoP in the static case. In [4] a motion capture system was used to track subject motion while a force platform was used to provide CoP data.

The need for a high-end motion capture system, limits the application of the method. A mobile measurement tool with a small set up time would make the SESC method available for wide scale application, especially for in-home rehabilitation. CoM based balance training for the elderly could be presented in the form of a game to enrich the user's

A. González, M. Hayashibe and P. Fraisse are with INRIA DEMAR Project and LIRMM, CNRS/University of Montpellier, France. \{gonzalezde, hayashibe, fraisse\}-at-lirmm.fr

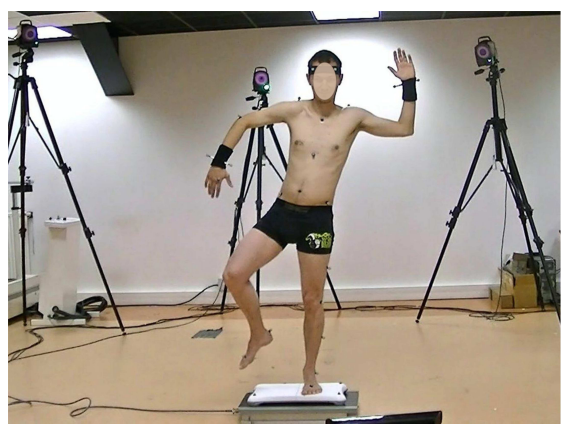

Fig. 1. Experimental setup for parallel measurement of Kinect-Wii board and Vicon-force plate.

experience [5]. In [6] we demonstrated that it is possible to apply the method to data obtained with a Kinect sensor after identification performed using a Wii balance board. In this paper, we aim at comparing the result of CoM estimation using a SESC identified with a Kinect and a Wii board to a SESC obtained using a Vicon system and an AMTI-OR6 force plate.

\section{Material And Methods}

The Vicon system is capable of video-based motion tracking using the positions of several markers in 3D. Additionally, it deals with the synchronization of analogue data such as force plate information or EMG signals. During identification, we measure the subject's CoP using an AMTI-OR6 force plate. Parallel to the Vicon recording, we capture the subject's movements using a Kinect to measure his pose and a Wii balance board for CoP information; (see Fig. 1). Processing of the Kinect data is done with the OpenNI-Primesense middleware (http://www.openni.org), while Wii board data is obtained using the Wiiuse project (http://github.com/rpavlik/wiiuse).

In order to find the parameters of the SESC chain, healthy subjects were asked to hold a number of different static poses. Each pose was measured using 1) an 8 camera Vicon system with a marker placement which followed Plug-InGait recommendations and 2) a Kinect placed in front of the subject, 3 meters away. Ground reaction force data was measured for identification and validation purposes using 1) an AMTI-OR6 platform 2) a Wii board. To obtain information from both devices at the same time, the Wii board was placed on top of the force plate during the test. Ground reaction forces were used to synchronize the Kinect and Vicon recordings. 

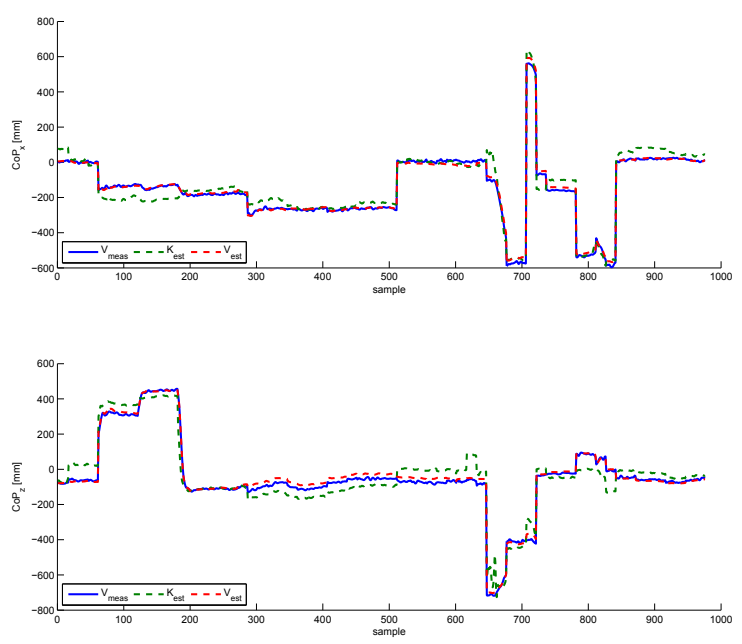

Fig. 2. Estimation of CoM position for the validation data set (Sb01). The plots indicate $\mathrm{CoP}$ position measured with the force plate ( $\left.V_{\text {meas }}\right)$, the estimated CoM $K_{\text {est }}$ and $V_{\text {est }}$ from the SESC models established with Kinect and Vicon measurements respectively.

Angular measurements from the Kinect and Vicon systems and ground reaction data were resampled at $15 \mathrm{~Hz}$ and filtered to remove noise. A second order, low-pass Butterworth filter with a cut-off frequency of $5 \mathrm{~Hz}$ was used. Only static poses should be used for the model's identification, due to this the data was divided into 1 second long windows to be analyzed. If the time window was considered static, it was accepted into the identification set. Two equivalent, 11 parameter SESCs were identified. The first from Vicon-force plate data, while the second one was estimated using the Kinect-Wii board information. The base of each chain was attached to the right ankle joint of their corresponding skeleton. Once the SESC model is identified from the experimental data, the subjectspecific CoM can be computed from the subject's posture information alone. That is to say, no CoP measurements are needed to estimate CoM position. To evaluate the estimation accuracy of each chain, the estimated CoM projection to the ground plane was compared to $\mathrm{CoP}$ measurements obtained from its original ground reaction sensor.

\section{Results}

The identified SESCs closely follow the measured CoP position (see Fig. 2). Results are given in the Kinect reference frame, where the $z$ axis runs in the anterior posterior direction while the $x$ axis runs from the subject's left to right side. Table I shows the root mean square error (rmse) between measured CoP and estimated CoM for two subjects. The identification set represents a direct validation, comparing the estimation to the data used for model identification; whereas the cross-validation set shows the model's performance with data not used during identification. The rms error, for one of the subjects, in the cross-validation set is $23.64 \mathrm{~mm}$ with the Kinect and $9.04 \mathrm{~mm}$ with the Vicon system. We also show the condition number (cond) of the configuration matrix used for identification; their small values indicate a high reliability of the solutions.
TABLE I

RESULTS FOR THE SESC PARAMETER IDENTIFICATION

\begin{tabular}{|c|c|c|c|c|c|c|}
\hline \multirow{4}{*}{$\begin{array}{l}\bar{\delta} \\
\text { D }\end{array}$} & \multirow[b]{3}{*}{ Kinect-Wii board } & \multirow{3}{*}{$\frac{\text { cond }}{7.04}$} & \multicolumn{2}{|c|}{ Identification } & \multicolumn{2}{|c|}{ Cross-validation } \\
\hline & & & $\mathrm{rmse}_{x}$ & $\mathrm{rmse}_{z}$ & $\mathrm{rmse}_{x}$ & $\mathrm{rmse}_{z}$ \\
\hline & & & 23.10 & 27.08 & 26.48 & 36.84 \\
\hline & Vicon-force plate & 9.03 & 11.63 & 14.87 & 10.46 & 15.08 \\
\hline \multirow{2}{*}{$\begin{array}{l}\text { ¿ } \\
\text { के } \\
\text { की }\end{array}$} & Kinect-Wii board & 8.27 & 23.87 & 19.60 & 26.06 & 20.95 \\
\hline & Vicon-force plate & 7.59 & 8.05 & 7.07 & 8.15 & 9.85 \\
\hline
\end{tabular}

${ }^{*}$ Rmse values for each direction $\left(\mathrm{rmse}_{j}\right)$ are given in $\mathrm{mm}$.

\section{Discussion AND CONCLUSION}

The SESC obtained using Vicon-force plate data is, unsurprisingly, more accurate at tracking CoP. However, it is not appropriate for in-home use. In this paper we have evaluated the performance of a SESC established with portable sensors. Even with a decreased accuracy, the SESC obtained using the Kinect and Wii board closely follows the one identified using the Vicon and AMTI force plate. This is an encouraging result to support the use of a portable system for CoM estimation with only Kinect skeleton measurements as input. The use of widely available hardware in such a system makes it suitable for the in-home rehabilitation scenario.

Information regarding CoM position is important for fall prevention as it could be extended to stability analysis during standing or walking. Commonly, an anthropometric table is used to estimate a subject's CoM position. However different mass distributions are to be expected for different populations. This is especially true for elderly subjects. These modeling errors can often result in an incorrect CoM estimation, which in turn leads to a bad evaluation of posture stability. This work can help improve the quality of the model by making it subject-specific. Following a short calibration, CoM position estimates become available by measuring the subject's pose alone. Currently experimentation and analysis with a larger number of subjects is ongoing in order to confirm the validity of the proposed method.

\section{REFERENCES}

[1] "World Population Ageing," Population Division of the Department of Economic and Social Affairs of the United Nations. Population Division of the Department of Economic and Social Affairs of the United Nations, 2009.

[2] H. M. Schepers, E. H. F. van Asseldonk, J. H. Buurke, and P. H. Veltink, "Ambulatory estimation of center of mass displacement during walking." IEEE transactions on bio-medical engineering, vol. 56, no. 4, pp. 1189-95, Apr. 2009.

[3] M. A. Jaffrey, "Estimating Centre of Mass Trajectory and SubjectSpecific Body Segment Parameters Using Optimisation Approaches," PhD, Victoria University, 2008.

[4] S. Cotton, A. Murray, and P. Fraisse, "Estimation of the Center of Mass: From Humanoid Robots to Human Beings," IEEE/ASME Transactions on Mechatronics, vol. 14, no. 6, pp. 707-712, Dec. 2009.

[5] M. W. Kennedy, J. P. Schmiedeler, C. R. Crowell, M. Villano, A. D. Striegel, and J. Kuitse, "Enhanced feedback in balance rehabilitation using the Nintendo Wii Balance Board," in 2011 IEEE 13th International Conference on e-Health Networking, Applications and Services. IEEE, Jun. 2011, pp. 162-168.

[6] A. González, M. Hayashibe, and P. Fraisse, "Estimation of the Center of Mass with Kinect and Wii balance board," in to appear in 2012 IEEE/RSJ International Conference on Intelligent Robots and Systems, 2012. 